Short Note

\title{
3-Chloro-4-fluoro- $\mathrm{N}$-\{[3-(4-methoxyphenyl)-1-phenyl-1H- pyrazol-4-yl]methyl $\}$ aniline
}

\author{
Sandhya Bawa, Fasih Ahmad and Suresh Kumar* \\ Department of Pharmaceutical Chemistry, Faculty of Pharmacy, Jamia Hamdard (Hamdard \\ University), New Delhi-110062, India
}

* Author to whom correspondence should be addressed; E-Mail: sureshkr.2006@gmail.com.

Received: 12 October 2009 / Accepted: 29 October 2009 / Published: 5 November 2009

\begin{abstract}
A direct reductive amination of 3-(4-methoxyphenyl)-1-phenyl-1H-pyrazole-4carbaldehyde 2 with 3-chloro-4-flouroaniline using $\mathrm{NaBH}_{4} / \mathrm{I}_{2}$ as a reducing agent is described. The reaction was carried out in $\mathrm{MeOH}$ under neutral conditions at room temperature to give the secondary amine, 3-chloro-4-fluoro- $N$ - $\{[3-(4-m e t h o x y p h e n y l)-1$ phenyl-1H-pyrazol-4-yl]methyl $\}$ aniline (3).
\end{abstract}

Keywords: reductive amination; pyrazolylamine; $\mathrm{NaBH}_{4} / \mathrm{I}_{2}$

\section{Introduction}

The direct reductive amination of aldehydes and ketones with a metal hydride reagent is one of the most useful methods for the synthesis of secondary and tertiary amines [1-4]. Secondary amines and their derivatives constitute many biologically active molecules and are important intermediates in the synthesis of active pharmaceutical ingredients, dyes, and fine chemicals [5-7]. In continuation of our interest in the synthesis of heteroaryl amines [8], we report herein the reductive amination of 3-(4-methoxyphenyl)-1-phenyl-1H-pyrazole-4-carbaldehyde 2 with 3-chloro-4-flouroaniline using $\mathrm{NaBH}_{4} / \mathrm{I}_{2}$ as reducing agent.

\section{Result and Discussions}

In the present study, a synthesis of 3-chloro-4-fluoro- $N$-\{[3-(4-methoxyphenyl)-1-phenyl-1Hpyrazol-4-yl]methyl $\}$ aniline (3) is reported from 3-(4-methoxyphenyl)-1-phenyl-1H-pyrazole-4- 
carbaldehyde 2 and 3-chloro-4-fluoroaniline via direct reductive amination using $\mathrm{NaBH}_{4} / \mathrm{I}_{2}$ as a reducing agent. The functional group transformation of compound $\mathbf{2}$ into $\mathbf{3}$ was established on the basis of IR, ${ }^{1} \mathrm{H}$ and ${ }^{13} \mathrm{C}$ NMR and mass spectral data. In the ${ }^{1} \mathrm{H}$ NMR spectrum of compound 2, the aldehydic proton signal at $9.95 \mathrm{ppm}$ disappeared and a new signal of $-\mathrm{CH}_{2} \mathrm{NH}$ - arose in the spectrum of compound 3 due to reductive amination. It appears at $4.17 \mathrm{ppm}$ as a doublet which suggests coupling with the NH proton $(J=4.8 \mathrm{~Hz})$. Moreover, in the ${ }^{13} \mathrm{C}$ NMR spectrum the aldehydic carbon of compound $\mathbf{2}$ after transforming into the secondary amine showed a new carbon signal at $39.92 \mathrm{ppm}$. The complete spectral details of compound $\mathbf{2}$ and $\mathbf{3}$ are disclosed in the experimental part. The values are in complete agreement with the structure assigned.

Scheme 1. Synthetic route to the title compound 3.

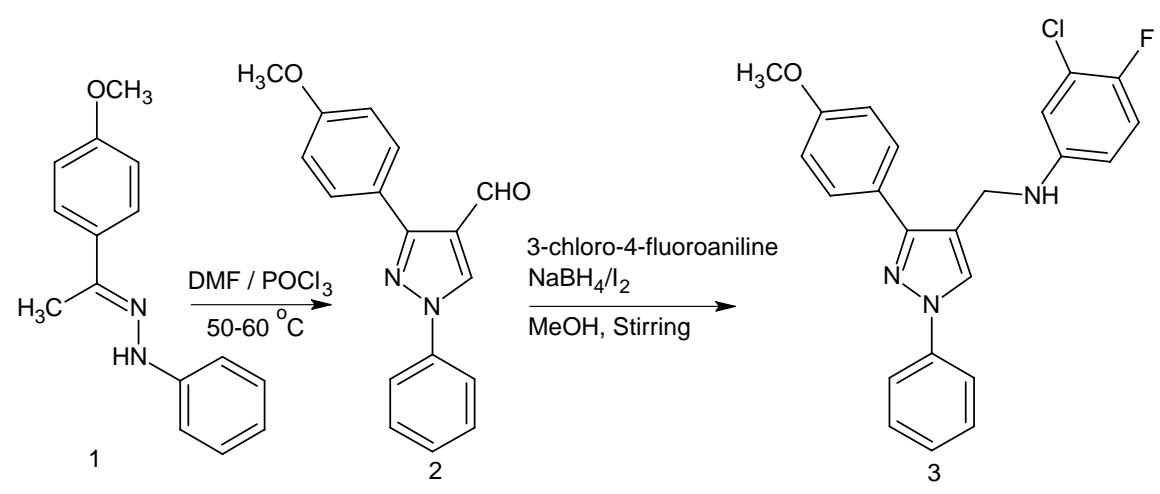

\section{Experimental}

The starting material 3-(4-methoxyphenyl)-1-phenyl-1H-pyrazole-4-carbaldehyde 2 was synthesized based on a literature method [9].

\subsection{3-(4-Methoxyphenyl)-1-phenyl-1H-pyrazole-4-carbaldehyde 2}

1-(1-(4-methoxyphenyl)ethylidene)-2-phenylhydrazine 1 (3.6 g, $0.015 \mathrm{~mol})$ was added to a cold $\left(4-6{ }^{\circ} \mathrm{C}\right)$ solution of DMF $(25 \mathrm{~mL})$, then $\mathrm{POCl}_{3}(5 \mathrm{~mL})$ was added and the resulting mixture was stirred at $50-60{ }^{\circ} \mathrm{C}$ for $6 \mathrm{~h}$. The mixture was poured into ice-cold water. A saturated solution of sodium bicarbonate was added to neutralize the mixture, the solid precipitate was filtered, washed with water, dried and recrystallized from ethanol.

Yield, 70\%; m.p. $130{ }^{\circ} \mathrm{C}$; creamy white crystalline solid.

IR $(\mathrm{KBr}) \mathrm{cm}^{-1}: 1603(\mathrm{C}=\mathrm{N}), 1522(\mathrm{C}=\mathrm{C}), 1053(\mathrm{C}-\mathrm{N}), 1710(\mathrm{C}=\mathrm{O})$.

${ }^{1} \mathrm{H}$ NMR $\left(300 \mathrm{MHz}, \mathrm{DMSO}-d_{6}\right): \delta 3.81\left(\mathrm{~s}, 3 \mathrm{H}, \mathrm{OCH}_{3}\right), 7.03-7.06(\mathrm{~m}, 2 \mathrm{H}, \mathrm{Ar}-\mathrm{H}), 7.45-7.48(\mathrm{~m}, 1 \mathrm{H}$, Ar-H), 7.53-7.56 (m, 2H, Ar-H), 7.88 (d, 2H, Ar-H, J=8.9 Hz), 7.96 (d, 2H, Ar-H, J = 7.8 Hz), 9.28 (s, 1H, pyrazole-H-5), $9.95(\mathrm{~s}, 1 \mathrm{H}, \mathrm{CHO})$.

${ }^{13} \mathrm{C}$ NMR (75 MHz, DMSO-d $) \delta$; $56.09\left(\mathrm{OCH}_{3}\right), 119.07,125.86,126.36,127.62,127.98,128.67$, 129.17, 131.07, 134.58, 139.49, 146.08, 151.88. 176.98 (CHO).

Anal. Calcd for $\mathrm{C}_{17} \mathrm{H}_{14} \mathrm{~N}_{2} \mathrm{O}_{2}$ : C, 73.37; H, 5.07; N, 10.07. Found: C, 73.69; H, 5.03; N, 10.12 . 


\subsection{3-Chloro-4-fluoro- $N$-\{[3-(4-methoxyphenyl)-1-phenyl-1H-pyrazol-4-yl]methyl\}aniline 3}

To a solution of 3-(4-methoxyphenyl)-1-phenyl-pyrazole-4-carboxaldehyde (0.278 g, $0.001 \mathrm{~mol})$ in $10 \mathrm{~mL}$ of methanol, 3-chloro-4-flouroaniline $(0.145 \mathrm{~g}, 0.001 \mathrm{~mol})$ and iodine $(0.051 \mathrm{~g}, 0.002 \mathrm{~mol})$ were added with stirring at room temperature. To the stirred solution, sodium borohydride $(0.055 \mathrm{~g}$, $0.015 \mathrm{~mol}$ ) was added slowly. Stirring was continued for $2 \mathrm{~h}$. The precipitate formed was filtered, washed with water, dried and recrystallized from ethanol. The progress of reaction and purity of the compound was checked by TLC, using benzene:acetone (9:1) as mobile phase.

Yield, 73\%; m.p. $117^{\circ} \mathrm{C}$; white-fluffy solid.

IR $(\mathrm{KBr}) \mathrm{cm}^{-1}: 1610(\mathrm{C}=\mathrm{N}), 1536(\mathrm{C}=\mathrm{C}), 993(\mathrm{C}-\mathrm{N})$.

${ }^{1} \mathrm{H}$ NMR (300 MHz, DMSO-d $)$ ): $\delta 3.77$ (s, 3H, $\mathrm{OCH}_{3}$ ), 4.17 (d, 2H, $\left.\mathrm{CH}_{2}, J=4.8 \mathrm{~Hz}\right), 6.17$ (t, $1 \mathrm{H}, \mathrm{NH}$, $J=4.5 \mathrm{~Hz}), 6.60-6.63(\mathrm{~m}, 1 \mathrm{H}, \mathrm{Ar}-\mathrm{H}), 6.75-6.78(\mathrm{~m}, 1 \mathrm{H}, \mathrm{Ar}-\mathrm{H}), 6.99-7.15(\mathrm{~m}, 3 \mathrm{H}, \mathrm{Ar}-\mathrm{H}), 7.29(\mathrm{t}, 1 \mathrm{H}$, Ar-H, $J=7.2 \mathrm{~Hz}), 7.49$ (t, 2H, Ar-H, $J=7.9 \mathrm{~Hz}), 7.72$ (d, 2H, Ar-H, $J=8.7 \mathrm{~Hz}), 7.85$ (d, 2H, Ar-H, $J=7.8 \mathrm{~Hz}), 8.54$ (s, $1 \mathrm{H}$, pyrazole $\mathrm{H}-5)$.

${ }^{13} \mathrm{C}$ NMR (75 MHz, DMSO-d 6$) \delta ; 39.92\left(\mathrm{CH}_{2}\right), 56.33\left(\mathrm{OCH}_{3}\right), 113.86,115.42,118.52,126.38$, $127.69,127.93,129.34,130.13,137.50,139.73,144.25,150.96,154.47,157.63$.

FAB-MS m/z: $408(\mathrm{M}+1)$.

Anal. Calcd for $\mathrm{C}_{23} \mathrm{H}_{19} \mathrm{ClFN}_{3} \mathrm{O}$ : C, 67.73; H, 4.70; N, 10.30. Found: C, 68.08; H, 4.73; N, 10.35 .

\section{Acknowledgement}

One of the authors (F.A.) expresses sincere thanks to AICTE, New Delhi for financial assistance. Thanks are due to Department of Pharmaceutical Chemistry, Faculty of Pharmacy, for providing the necessary facilities and Central drug Research Institute (CDRI), Lucknow, India for recording spectral data.

\section{References}

1. Alinezhad, H.; Tajbakhsh, M.; Salehian, F.; Fazil, K. Reductive amination of aldehydes and ketones to their corresponding amines with $\mathrm{N}$-methylpyrrolidine zinc borohydride. Tetrahedron Lett. 2009, 50, 659-661.

2. Heydari, A.; Khaksar, S.; Akbari, J.; Esfandyari, M.; Pourayoubi, M.; Tajbakhsh, M. Direct reductive amination and selective 1,2-reduction of $\alpha, \beta$-unsaturated aldehydes and ketones by $\mathrm{NaBH}_{4}$ using $\mathrm{H}_{3} \mathrm{PW}_{12} \mathrm{O}_{40}$ as catalyst. Tetrahedron Lett. 2007, 48, 1135-1138.

3. Saidi, M.R.; Brown, R.S.; Ziyaei-Halimjani, A. Reductive amination of aldehydes with sodium borohydride and lithium aluminum hydride in the presence of lithium perchlorate. J. Iran. Chem. Soc. 2007, 04, 194-198.

4. Baxter, E.W.; Reitz, A.B. Reductive aminations of carbonyl compounds with borohydride and borane reducing agents. In Organic Synthesis; Wiley InterScience: New York, NY, USA, 2002; Vol. 59. 
5. Bhandari, K.; Srivastava, S.; Shanker, G.; Nath, C. Substituted propanolamines and alkylamines derived from fluoxetine as potent appetite suppressants. Bioorg. Med. Chem. 2005, 13, 1739-1747.

6. Delarue-Cochin, S.; Paunescu, E.; Maes, L.; Mouray, E.; Sergheraert, C.; Grellier, P.; Melnyk, P. Synthesis and antimalarial activity of new analogues of amodiaquine. Eur. J. Med. Chem. 2008, 43, 252-260.

7. Varandas, L.S.; Fraga, C.A.M.; Miranda, A.L.P.; Barreiro, E.J. Design, synthesis and pharmacological evaluation of new nonsteroidal antiinflammatory 1,3,4-thiadiazole derivatives. Lett. Drug Des. Discovery 2005, 2, 62-67

8. Kumar.S.; Bawa, S.; Drabu, S. N-[(2-Chloro-6-methylquinolin-3-yl)methyl]aniline. Molbank 2009, M618.

9. Prakash, O.; Pannu, K,; Kumar, A. Synthesis of some new 2-(3-aryl-1-phenyl-4-pyrazolyl)benzoxazoles using hypervalent iodine mediated oxidative cyclization of Schiff bases. Molecules 2006, 11, 43-48.

Sample Availability: Sample of the compound $\mathbf{3}$ is available from authors.

(C) 2009 by the authors; licensee Molecular Diversity Preservation International, Basel, Switzerland. This article is an open-access article distributed under the terms and conditions of the Creative Commons Attribution license (http://creativecommons.org/licenses/by/3.0/). 